\title{
Apical hypertrophic cardiomyopathy, a review of presentation, pathophysiology, diagnosis and natural course of the disease
}

\author{
Ali Osama Malik ${ }^{1}$, Subodh Devabhaktuni², Oliver Abela², Jimmy Diep², Chowdhury H. Ahsan², Arhama Aftab Malik ${ }^{3}$
}

\begin{abstract}
Apical Hypertrophic Cardiomyopathy is an uncommon phenotype of hypertrophic cardiomyopathy. We present a review of best evidence on presentation, pathophysiology, diagnosis, outcomes and

\section{Introduction:}

Apical Hypertrophic Cardiomyopathy (AHCM) is characterized by hypertrophy of the myocardium predominantly in the left ventricular (LV) apex and has now been recognized as an uncommon phenotype of hypertrophic cardiomyopathy ( $\mathrm{HCM}) .{ }^{1}$ The incidence of $\mathrm{AHCM}$ ranges from $3 \%$ of all $\mathrm{HCM}$ patients in North America to up to $15 \%$ and $16 \%$ in reports from Japan and China respectively. ${ }^{2,3}$ We review the latest evidence on epidemiology, pathophysiology, diagnostic modalities, management and natural course of AHCM.
\end{abstract}

management for patients with apical hypertrophic cardiomyopathy.

Key Words: Apical Hypertrophic Cardiomyopathy, Mimics, Incidence, Natural Course, Diagnosis

(Bangladesh Heart Journal 2016; 31(1) : 29-36)

\section{Typical Presentation}

In a cohort of 208 patients from China, the most common symptom was chest discomfort that was characterized as chest pain, chest tightness and palpitations. ${ }^{3}$ In another study $46 \%$ of the patients were asymptomatic. ${ }^{4}$ In another cohort of 105 patients, $16 \%$ complained of angina, $14 \%$ had atypical chest pain, $10 \%$ had palpitations, $6 \%$ complained of dyspnea, and $6 \%$ had pre-syncope. 5

\section{Diagnostic considerations and types of AHCM}

The diagnosis is made on imaging studies. ${ }^{6}$ On transthoracic echocardiogram(TTE) AHCM is defined as LV wall thickening confined to the most distal region of the apex, below the papillary muscle level with the ratio of

1. University of Nevada School of Medicine, Department of Internal Medicine, Las Vegas, Nevada, 89146

2. University of Nevada School of Medicine, Department of Cardiovascular Medicine, Las Vegas, Nevada, 89146

3. Aga Khan University Medical College, Karachi, Pakistan 74800" apical to basal LV thickness more than $1.3 .{ }^{6,7}$ Hypertrophy at this region is best visualized in apical views. ${ }^{7}$ In a cohort of 182 patients with AHCM 3 subtypes were identified based on the patterns of hypertrophy. These subtypes are pure, pure diffuse and mixed. ${ }^{8}$

AHCM is more commonly classified as "pure" when no concomitant septal hypertrophy is present, and "mixed" when evidence of septal hypertrophy is seen. ${ }^{3,9}$ In two studies no significant difference was found between cardiovascular mortality and morbidity between these variants of $\mathrm{AHCM}{ }^{3,5}$ Figure $1 \mathrm{~A}$ and $1 \mathrm{~B}$ show an illustration of the location of hypertrophy and differences between the two variants.

\section{Echocardiography-strengths and limitations}

TTE is usually the first line imaging modality in patients suspected to have AHCM, because of its widespread availability and relatively low cost. Figure 2 shows typical finding of pure variant of AHCM on TTE.

Frequent inability to visualize the apical endocardium can limit diagnosis of AHCM by TTE. ${ }^{10,11}$ Furthermore the distribution of hypertrophy may be inappropriately measured on TTE and severity of wall thickening may be underestimated. ${ }^{12}$ In a study TTE only detected one in four cases of AHCM related LV aneurysms. ${ }^{13}$ Even in classic HCM patients TTE was only able to identify LV aneurysm in $57 \%$ of the patients. ${ }^{14}$ Hence additional imaging modalities are recommended in patients with suspicion of AHCM and initial TTE is non-diagnostic or with sub optimal visualization of the apex. 


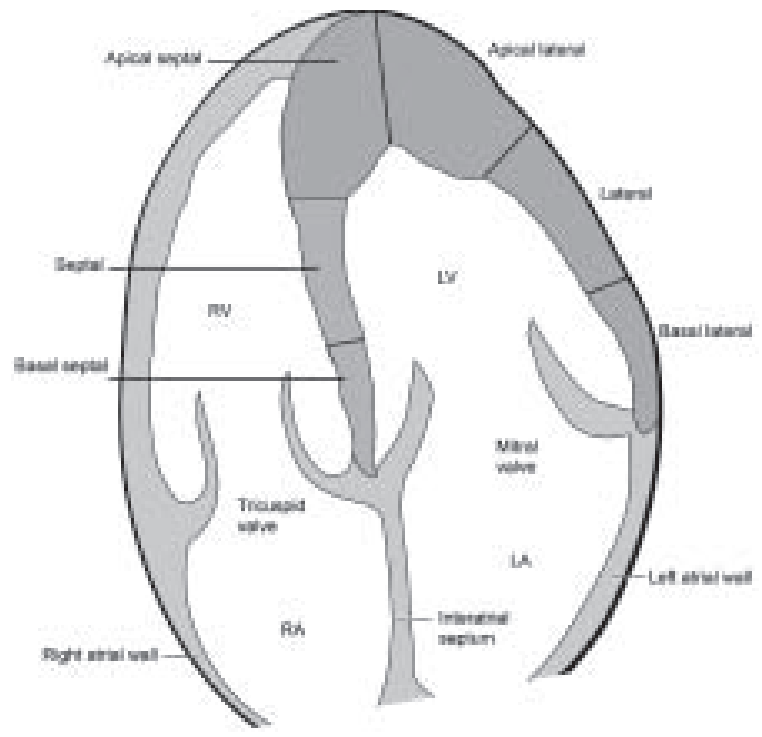

(A)

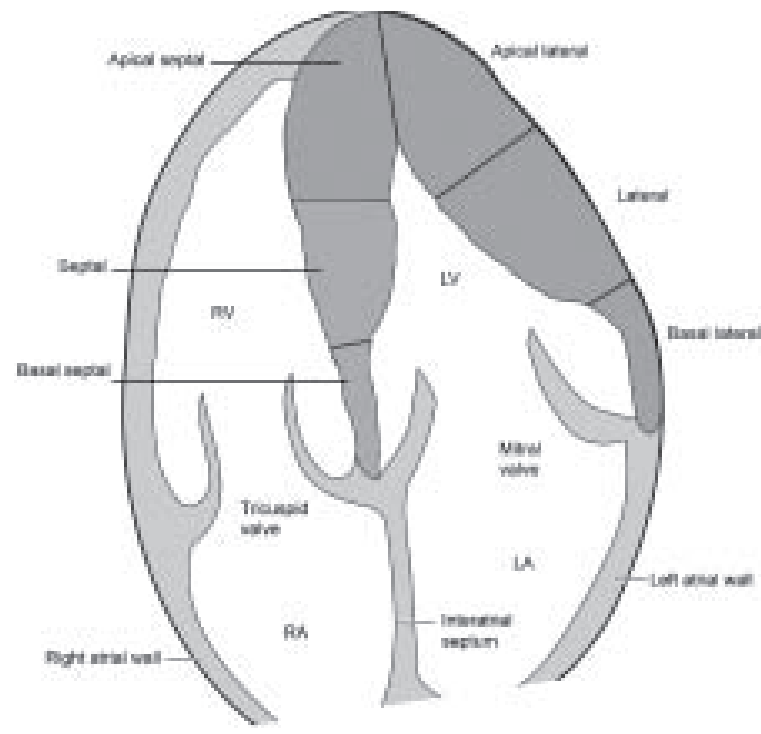

(B)

Fig.-1: Pattern of hypertrophy A) pure variant of Apical Hypertrophic Cardiomyopathy (AHCM), B) mixed variant of AHCM

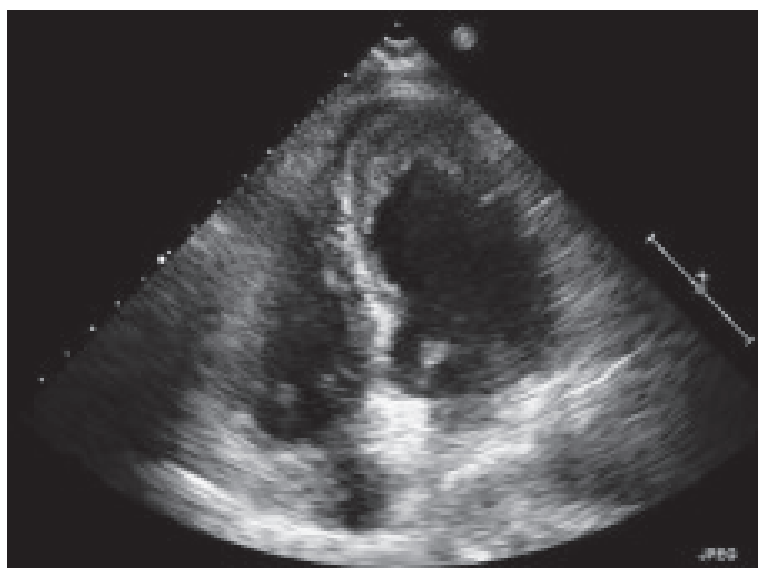

Fig.-2: Representative trans-thoracic echocardiogram image of pure variant of apical hypertrophic cardiomyopathy

\section{Apical hypertrophic cardiomyopathy mimics and the} role of other imaging modalities

As mentioned a TTE although often the first line imaging modality can be non-diagnostic for AHCM especially if the apex is not fully visualized. Furthermore apical thrombus, Loefflers endocarditis, LV aneurysm, LV non compaction, and endomyocardial fibrosis may give a similar echocardiographic appearance on TTE to AHCM. ${ }^{15-17}$ Other common imaging modality options include TTE with contrast, trans-esophageal echocardiogram (TEE), cardiac multidetector computer tomography (MDCT) and cardiac magnetic resonance imaging (CMR).

Apical ballooning syndrome or Takotsubo cardiomyopathy can also mask underlying AHCM. ${ }^{18}$ In such cases TTE with contrast can be helpful. ${ }^{18}$ Figure $3 \mathrm{~A}$ shows typical findings on TTE in Takotsubo cardiomyopathy. TTE with contrast can also help in differentiating LV thrombus and LV non-compaction from AHCM. ${ }^{18}$ Figure $3 \mathrm{~B}$ and $3 \mathrm{C}$ show representative images of typical findings on TTE in LV thrombus and LV non compaction respectively.

TTE with contrast can help in diagnosing AHCM in patients with high suspicion and a non-diagnostic TTE. ${ }^{10}$ TEE can also accurately measure wall thickness at the apex if TTE imaging is not adequate. ${ }^{12}$

In recent years there has been a great increase in the use of CMR in the diagnosis of HCM including AHCM, because of its precise determination of myocardial anatomy and the depiction of myocardial fibrosis. ${ }^{15} \mathrm{CMR}$ has also been shown to distinguish pure from mixed variant of AHCM. ${ }^{19}$ In a small cohort of ten patients with non-diagnostic TTE, AHCM was seen on CMR. ${ }^{20} \mathrm{CMR}$ has shown better performance in detection AHCM compared to TTE, and in also detecting LV aneurysms related to $\mathrm{AHCM} .{ }^{13}$ 


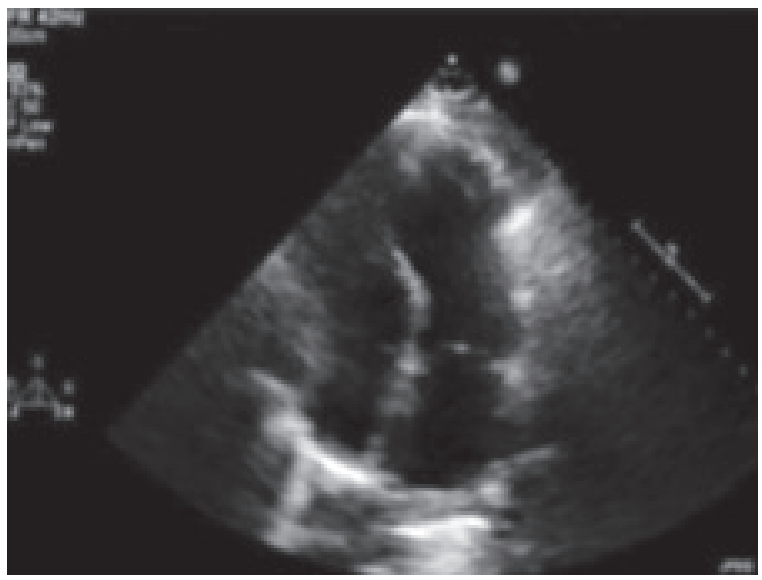

(A)

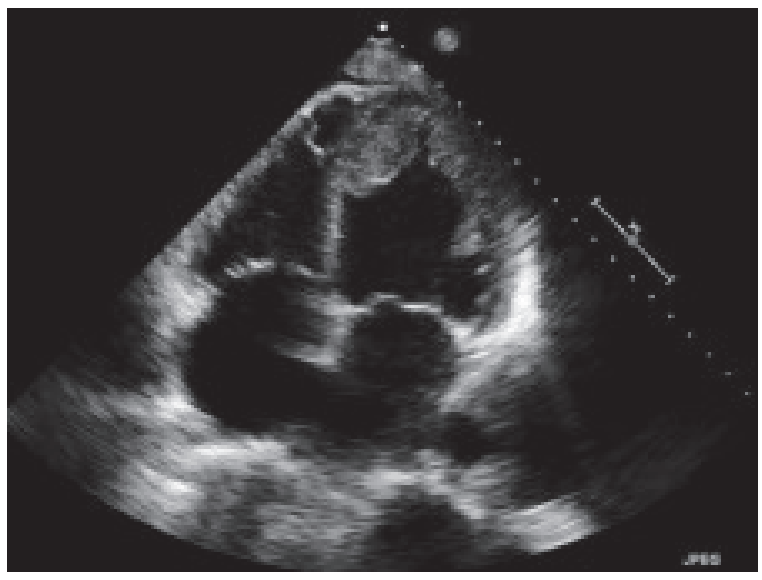

(B)

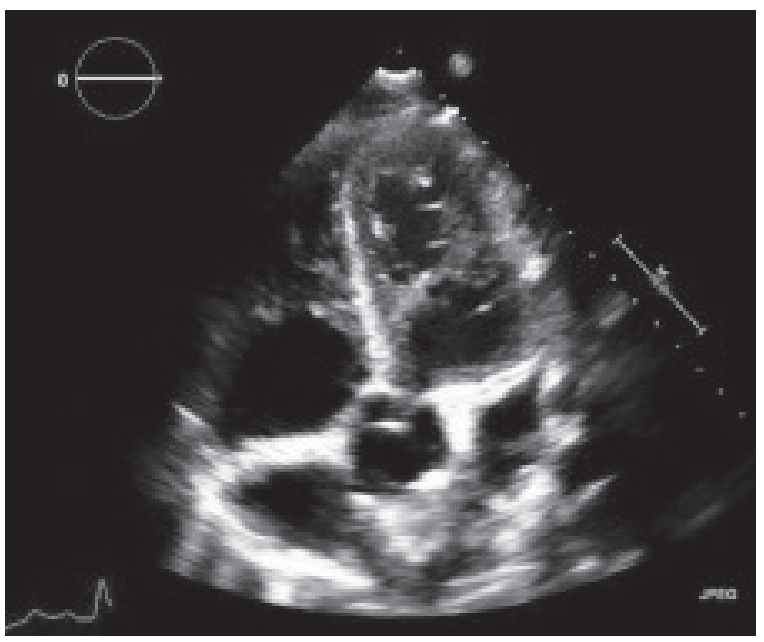

(C)

Fig.-3: A) Representative 2D transthoracic echocardiogram images of Takatsubo Cardiomyopathy B) Patient with left ventricle(LV) thrombus, C) LV non compaction

Characteristic findings on single photon emission computed topography (SPECT) imaging can also aid in diagnosis. In a cohort of 20 patients with $\mathrm{AHCM}, 75 \%$ demonstrated an increased tracer uptake and characteristic spade-like deformity of the LV chamber. ${ }^{21}$ Evaluation of the LV cavity on ventriculogram can also show the spade-like configuration of LV in end diastole. ${ }^{21}$

MDCT has been used with success to detect significant coronary artery stenosis and has also emerged as a novel technique to evaluate cardiac morphology. Due to its high spatial resolution MDCT enables accurate delineation of apical endocardial border and dynamic evaluations of myocardial thickness and global and regional LV function. ${ }^{22}$

Table 1 shows the sensitivity of some of the imaging

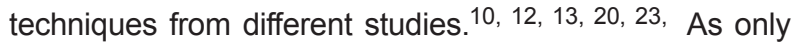
positive results from the modality being tested resulted in a confirmatory gold standard test being performed, specificities of imaging modalities could not be calculated. Although TTE has low sensitivity it has the advantage of having a low cost and widespread availability. A reasonable alternative could be TTE with contrast. 
Table-I

Sensitivity of different imaging modalities in diagnosing AHCM

\begin{tabular}{lcccc}
\hline Author & Imaging Modality Studied & Sample Size & Gold Standard & Sensitivity \\
\hline Crowley JJ12 & TEE & 6 & Previous Diagnosis & $100 \%$ \\
Crowley JJ12 & TTE & 6 & Previous Diagnosis & $83 \%$ \\
Fatori R $\mathrm{R}^{13}$ & TTE & 13 & CMR & $69 \%$ \\
Moon JC & TTE & 10 & CMR & 0 \\
Ward RP $\mathrm{RP}^{10}$ & TTE & 26 & TTE with contrast & 0 \\
Chen CC $\mathrm{CC}^{23}$ & MDCT & 14 & Previous diagnosis & $100 \%$ \\
\hline
\end{tabular}

\section{Electrocardiography}

The electrocardiogram (EKG) findings that have been associated with $\mathrm{AHCM}$ include deep inverted $\mathrm{T}$ waves in precordial leads, and presence of notched QRS in more than one lead. ${ }^{23-25} \mathrm{~T}$ wave inversions can disappear during long term follow-up. ${ }^{26}$ Figure $4 \mathrm{~A}$ shows an EKG with characteristic $\mathrm{T}$ wave inversions in precordial leads associated with $\mathrm{AHCM}$.

Presence of notched QRS without bundle branch block (BBB) is associated with impaired apical contraction and late gadolinium enhancement (LGE) on CMR, and is associated with higher prevalence of ventricular tachycardia. ${ }^{25}$ Reports have shown the association of a notched QRS in inferior leads with an apical aneurysm. ${ }^{27,28}$ Hence notched QRS without BBB may be a useful indicator of morbidity and risk of aneurysm formation in patients with AHCM. Figure 4B shows an EKG with notched QRS in inferior leads.

\section{Pathophysiology}

\section{Cellular mechanism and role of gene mutations}

Decades of intense investigation has identified more than 11 genes and 1400 mutations implicated in $\mathrm{HCM}^{29}$

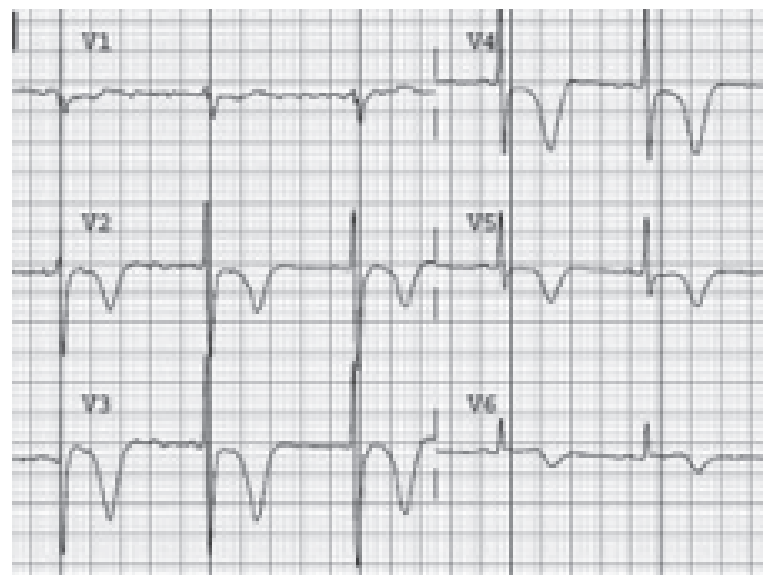

In AHCM the most common gene mutations are $\mathrm{MYH7}$, MYBPC3, ACTC1 and TPM1.1, 30,31 The protein coded by these genes plays an important role in the contraction of the sarcomere. ${ }^{32}$

The key histological feature of HCM is myocyte and myofibrillar disarray. ${ }^{33}$ Myocyte hypertrophy with nuclear enlargement and hyperchromasia is also seen. ${ }^{34}$ Dysplasia of small arteries seen as medial and intimal smooth muscle proliferation with luminal narrowing can also develop. ${ }^{35}$ The mechanism by which genetic mutations cause these changes is poorly understood. ${ }^{32}$

Prevalence of mutations does not correlate with phenotypic features. In the largest studied cohort of patients with AHCM only 18/71 (25\%) of the patients were genotype positive with majority of mutations found in $\mathrm{MYH7}$ and MYBPC $3 .{ }^{1}$ In another cohort of 61 patients gene mutations were found only in $8 / 61$ (13\%) of the patients. ${ }^{31}$ Furthermore genotype positive patients did not have any significant differences in outcomes.

\section{Natural course, morbidity and mortality}

Relative to $\mathrm{HCM}$, patients with $\mathrm{AHCM}$ have more benign outcomes. Incidence of sudden cardiac death (SCD),

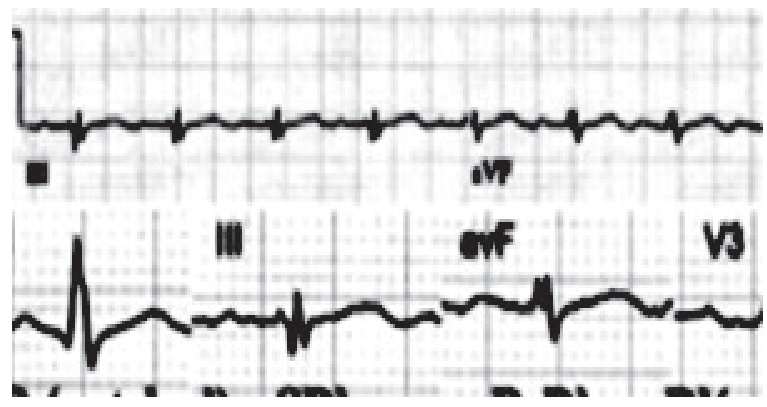

Fig.-4: A) Electrocardiogram showing characteristic GiantT wave inversions B) notched QRS associated with Apical Hypertrophic Cardiomyopathy 
cardiac dysrhythmias and heart failure is less frequent than HCM. ${ }^{37}$ However, common causes of cardiovascular mortality still include myocardial infarction, congestive heart failure, dysrhythmias and left ventricular apical aneurysms.3,38,39 To our knowledge only 10 studies, looking at long term outcomes in $\mathrm{AHCM}$, with a sample size greater than 30 , have been published. Symptoms at presentation were not specified in majority of the studies. Mortality and morbidity outcomes from these studies are summarized in Table 2 and Table 3.3, 4, 5, 16, 36, 37, 40${ }^{43}$ Most studies did not report Ml unrelated to pre-existing coronary artery disease.
AHCM patients have a relatively small burden of myocardial fibrosis and less severe diastolic dysfunction, hence have a better prognosis than HCM patients. ${ }^{43}$ Some of the common causes of long term cardiovascular morbidity in patients with AHCM include atrial fibrillation, stroke, transient ischemic attack, syncope, pre-syncope and myocardial infarction. In several of the major outcome studies, atrial fibrillation was the most common, followed by stroke. ${ }^{4,5}$ The incidence of atrial fibrillation is higher in mixed type. ${ }^{8}$ However another report showed a higher incidence of atrial fibrillation in patients with pure variant. ${ }^{9}$ The prognosis is worse in women with a higher

Table-II

Mortality rates in major studies for $\mathrm{AHCM} .{ }^{*}$ median follow-up, ${ }^{* *}$ not specified

\begin{tabular}{|c|c|c|c|c|c|c|}
\hline Author & Region & $\mathrm{N}$ & $\begin{array}{c}\text { Mean age at } \\
\text { presentation } \\
\text { (years) }\end{array}$ & $\begin{array}{c}\text { Mean } \\
\text { Follow-up } \\
\text { (years) }\end{array}$ & $\begin{array}{l}\text { All-Cause } \\
\text { mortality }\end{array}$ & $\begin{array}{c}\text { Cardiovascular } \\
\text { mortality }\end{array}$ \\
\hline Sukamoto T et all ${ }^{40}(1986)$ & China & 31 & 47 & $2-13$ & 0 & 0 \\
\hline Erickson MJ et all ${ }^{5}(2002)$ & Canada & 105 & 41.4 & $13.6 \pm 8.3$ & $11 / 105$ & 2/105 (1.9\%) \\
\hline Lee $\mathrm{CH}$ et all ${ }^{37}(2006)$ & Taiwan & 40 & 60 & $6 \pm 5$ & 0 & 0 \\
\hline Chung T et all ${ }^{41}(2010)$ & Australia & 32 & 71 & $4 \pm 3$ & $6 / 32$ & $4 / 32(13 \%)$ \\
\hline Chen CC et all ${ }^{42}(2011)$ & Taiwan & 47 & 60 & $2.95 \pm 1.97$ & $4 / 47$ & $3 / 47(6.4 \%)$ \\
\hline Moon J et all ${ }^{16}(2011)$ & Korea & 453 & 61 & $3.58 \pm 1.66$ & $39 / 453$ & $22 / 453$ (4.8) \\
\hline Yan L et all ${ }^{3}(2012)$ & China & 208 & 52 & ** & $3 / 193$ & $2 / 193(1.0 \%)$ \\
\hline Kim SH et all ${ }^{36}(2013)$ & Korea & 243 & 59 & $6.5^{\star}$ & $65 / 243$ & $26 / 243$ (11\%) \\
\hline KlarichKW et all ${ }^{4}(2013)$ & USA & 193 & 58 & ** & $55 / 187$ & $7 / 187$ (3.7\%) \\
\hline Kim EK et all ${ }^{43}(2015)$ & Korea & 85 & 56 & 37 months $^{*}$ & ** & 0 \\
\hline
\end{tabular}

Table-III

Percentage of Patients in Major Studies with Symptoms at Presentation and Major Morbid Clinical Outcomes( ${ }^{*}$ not specified in study. ${ }^{* *}$ New York Hear Association Functional Class >3)

Congestive Heart Failure (CHF), Atrial Fibrillation (Afib)

Ventricular Tachycardia/Ventricular Fibrillation (Vfib)

\begin{tabular}{|c|c|c|c|c|c|c|c|c|c|}
\hline \multirow[t]{2}{*}{ Author } & \multicolumn{2}{|c|}{ At Presentation } & \multirow{2}{*}{$\begin{array}{c}\text { Giant } \\
\text { t waves } \\
>10 \mathrm{~mm}\end{array}$} & \multirow{2}{*}{$\begin{array}{l}\text { Vfib/ } \\
\text { Vtach }\end{array}$} & \multirow{2}{*}{$\begin{array}{c}\text { Deep } \\
\text { inverted } \\
\text { t waves }\end{array}$} & \multirow[t]{2}{*}{ Afib } & \multirow[t]{2}{*}{ CHF } & \multirow[t]{2}{*}{ stroke } & \multirow{2}{*}{$\begin{array}{c}\text { Syncope/ } \\
\text { Pre-syncope }\end{array}$} \\
\hline & Asymptomatic & $\begin{array}{c}\text { Chest } \\
\text { Pain/ } \\
\text { Dypnea }\end{array}$ & & & & & & & \\
\hline Sukamoto T et all ${ }^{40}$ & * & 3.2 & * & 0 & 100 & * & * & * & * \\
\hline Erickson MJ et all ${ }^{5}$ & 46 & 30 & 47 & 3.8 & 93 & 12.4 & 4.8 & 2.9 & * \\
\hline Lee $\mathrm{CH}$ et all ${ }^{37}$ & * & 80 & 52.5 & 0 & * & 7.5 & & 1 & 15 \\
\hline Chung T et all ${ }^{41}$ & * & * & 46.8 & * & * & 31.2 & 9.3 & & 6.3 \\
\hline Chen CC et all ${ }^{42}$ & * & * & 59.6 & 4.2 & * & 14.8 & 25.5 & 10.6 & 10.6 \\
\hline Moon J et all ${ }^{16}$ & 78 & 7 & * & * & * & 16 & 15 & 6 & 1 \\
\hline Yan L et all ${ }^{3}$ & * & 91.8 & 28.8 & 2.6 & 91.3 & 9.9 & $7.2^{\star *}$ & 1.6 & 7.2 \\
\hline Kim SH et all ${ }^{36}$ & * & * & 36 & & * & * & * & & * \\
\hline Klarich KW et all ${ }^{4}$ & * & 28 & 11 & 11 & 90 & 29 & 8 & 11 & 15 \\
\hline Kim EK et all ${ }^{43}$ & * & * & * & 1.2 & * & * & * & 3.5 & 2.4 \\
\hline
\end{tabular}


incidence of heart failure and atrial fibrillation. ${ }^{4}$ The prognosis of AHCM becomes very poor with the development of apical aneurysms. ${ }^{38}$ It is not clear if myocardial infarction in the apex leads to aneurysm formation in these patients.

\section{Management Considerations}

The most recent guidelines, for management of patients with $\mathrm{HCM}$, by the American College of Cardiology and American Heart Association (ACC/AHA) were published in 2011. ${ }^{6}$ Risk stratification of AHCM patients, based on history of SCD, syncope, family history of SCD and ventricular tachycardia (VT) is reasonable. In such instances an intra-cardiac defibrillator (ICD) is recommended for the patient. ${ }^{6}$ However the ACC/AHA guidelines do not separately address AHCM.

\section{Future Directions for Research}

AHCM is still a poorly understood disease. There is a dearth of significant multi-center studies looking at long term follow-up in patients with AHCM. The outcome studies either have a very small sample size or short follow-up period. No significant study has been done to look at natural course specifically in the young population. The mechanisms underlying the differences in incidence and outcomes in patients from different ethnicities and gender are also unclear.

More basic science research is needed to understand the genetic and molecular interactions causing disease, at the cellular level. Little is known about the mechanism by which gene mutations result in myocyte disarray and hypertrophy. A better understanding regarding these complex mechanisms is necessary to improve treatment and outcomes.

In order to develop a more evidence based approach, there exists a need for more large scale population based studies to evaluate the most effective strategy for imaging known or suspected AHCM. More outcome based research is needed to evaluate the role of ICDs for primary prevention in patients with $\mathrm{AHCM}$. Having a central registry to document all cases of AHCM will lead to a better understanding about the pathophysiology and natural course of the disease.

\section{References:}

1. Towe EC, Bos JM, Ommen SR, Gersh BJ, Ackerman MJ. Genotype-phenotype correlations in apical variant hypertrophic cardiomyopathy. Congenit Heart Dis. 2015;10(3):E139-45.

2. Kitaoka H, Doi Y, Casey SA, Hitomi N, Furuno T, Maron BJ. Comparison of prevalence of apical hypertrophic cardiomyopathy in Japan and the United States. Am J Cardiol. 2003 2015;92(10):1183-6.

3. Yan L, Wang Z, Xu Z, Li Y, Tao Y, Fan C. Two hundred eight patients with apical hypertrophic cardiomyopathy in China: clinical feature, prognosis, and comparison of pure and mixed forms. Clin Cardiol. 2012;35(2):101-6.

4. Klarich $\mathrm{KW}$, Attenhofer Jost $\mathrm{CH}$, Binder J, Connolly HM, Scott CG, Freeman WK, et al. Risk of death in long-term follow-up of patients with apical hypertrophic cardiomyopathy. Am J Cardiol. 2013;111(12):1784-91.

5. Eriksson MJ, Sonnenberg B, Woo A, Rakowski P, Parker TG, Wigle ED, et al. Long-term outcome in patients with apical hypertrophic cardiomyopathy. J Am Coll Cardiol. 2002 Feb 20;39(4):638-45.

6. Gersh BJ, Maron BJ, Bonow RO, Dearani JA, Fifer MA, Link MS, et al. 2011 ACCF/AHA Guideline for the Diagnosis and Treatment of Hypertrophic Cardiomyopathy: a report of the American College of Cardiology Foundation/American Heart Association Task Force on Practice Guidelines. Developed in collaboration with the American Association for Thoracic Surgery, American Society of Echocardiography, American Society of Nuclear Cardiology, Heart Failure Society of America, Heart Rhythm Society, Society for Cardiovascular Angiography and Interventions, and Society of Thoracic Surgeons. J Am Coll Cardiol. 2011;58(25):e212-60.

7. Parisi R, Mirabella F, Secco GG, Fattori R. Multimodality imaging in apical hypertrophic cardiomyopathy. World J Cardiol. 2014;6(9):91623.

8. Choi EY, Rim SJ, Ha JW, Kim YJ, Lee SC, Kang DH, et al. Phenotypic spectrum and clinical characteristics of apical hypertrophic cardiomyopathy: multicenter echo-Doppler study. Cardiology. 2008;110(1):53-61.

9. Kubo T, Kitaoka H, Okawa M, Hirota T, Hoshikawa $\mathrm{E}$, Hayato K, et al. Clinical profiles of hypertrophic cardiomyopathy with apical phenotypecomparison of pure-apical form and distal-dominant form. Circ J. 2009 Dec;73(12):2330-6.

10. Ward RP, Weinert L, Spencer KT, Furlong KT, Bednarz J, DeCara J, et al. Quantitative diagnosis of apical cardiomyopathy using contrast 
echocardiography. J Am Soc Echocardiogr. 2002 Apr;15(4):316-22.

11. Prasad K, Atherton J, Smith GC, McKenna WJ, Frenneaux MP, Nihoyannopoulos P. Echocardiographic pitfalls in the diagnosis of hypertrophic cardiomyopathy. Heart. 1999 Nov;82 Suppl 3:III8-III15.

12. Crowley JJ, Dardas PS, Shapiro LM. Assessment of apical hypertrophic cardiomyopathy using transoesophageal echocardiography. Cardiology. 1997 Mar-Apr;88(2):189-96.

13. Fattori R, Biagini E, Lorenzini M, Buttazzi K, Lovato L, Rapezzi C. Significance of magnetic resonance imaging in apical hypertrophic cardiomyopathy. Am J Cardiol. 2010;105(11):1592-6.

14. Maron MS, Finley JJ, Bos JM, Hauser TH, Manning WJ, Haas TS, et al. Prevalence, clinical significance, and natural history of left ventricular apical aneurysms in hypertrophic cardiomyopathy. Circulation. 2008 Oct 7;118(15):1541-9.

15. Noureldin RA, Liu S, Nacif MS, Judge DP, Halushka MK, Abraham TP, et al. The diagnosis of hypertrophic cardiomyopathy by cardiovascular magnetic resonance. J Cardiovasc Magn Reson. 2012;14:17.

16. Moon J, Shim CY, Ha JW, Cho IJ, Kang MK, Yang WI, et al. Clinical and echocardiographic predictors of outcomes in patients with apical hypertrophic cardiomyopathy. Am J Cardiol. 2011;108(11):16149.

17. Chang SA, Kim HK, Park EA, Kim YJ, Sohn DW. Images in cardiovascular medicine. Loeffler endocarditis mimicking apical hypertrophic cardiomyopathy. Circulation. 2009 Jul 7;120(1):825.

18. Roy RR, Hakim FA, Hurst RT, Simper D, Appleton CP. Two cases of apical ballooning syndrome masking apical hypertrophic cardiomyopathy. Tex Heart Inst J. 2014;41(2):179-83.

19. Soler R, Rodriguez E, Rodriguez JA, Perez ML, Penas M. Magnetic resonance imaging of apical hypertrophic cardiomyopathy. J Thorac Imaging. 1997;12(3):221-5.

20. Moon JC, Fisher NG, McKenna WJ, Pennell DJ. Detection of apical hypertrophic cardiomyopathy by cardiovascular magnetic resonance in patients with non-diagnostic echocardiography. Heart. 2004;90(6):645-9.

21. Cianciulli TF, Saccheri MC, Masoli $\mathrm{OH}$, Redruello MF, Lax JA, Morita LA, et al. Myocardial perfusion SPECT in the diagnosis of apical hypertrophic cardiomyopathy. J Nucl Cardiol. 2009;16(3):391-5.

22. Kramer CM, Budoff MJ, Fayad ZA, Ferrari VA, Goldman C, Lesser JR, et al. ACCF/AHA2007 clinical competence statement on vascular imaging with computed tomography and magnetic resonance: a report of the American College of Cardiology Foundation/American Heart Association/American College of Physicians Task Force on Clinical Competence and Training: developed in collaboration with the Society of Atherosclerosis Imaging and Prevention, the Society for Cardiovascular Angiography and Interventions, the Society of Cardiovascular Computed Tomography, the Society for Cardiovascular Magnetic Resonance, and the Society for Vascular Medicine and Biology. Circulation. 2007;116(11):1318-35.

23. Chen CC, Chen MT, Lei MH, Hsu YC, Chung SL, Sung YJ. Assessing myocardial bridging and left ventricular configuration by 64 -slice computed tomography in patients with apical hypertrophic cardiomyopathy presenting with chest pain. J Comput Assist Tomogr. Jan;34(1):70-4.

24. Malik LH, Singh GD, Amsterdam EA. T-wave tease: apical hypertrophic cardiomyopathy. Am J Med. Jun;127(6):498-500.

25. Sakamoto T, Tei C, Murayama M, Ichiyasu H, Hada $Y$. Giant $T$ wave inversion as a manifestation of asymmetrical apical hypertrophy (AAH) of the left ventricle. Echocardiographic and ultrasonocardiotomographic study. Jpn Heart J. 1976;17(5):611-29.

26. Suwa K, Satoh H, Sano M, Nobuhara M, Saitoh T, Saotome M, et al. Functional, morphological and electrocardiographical abnormalities in patients with apical hypertrophic cardiomyopathy and apical aneurysm: correlation with cardiac MR. Open Heart.1(1):e000124.

27. Koga $\mathrm{Y}, \mathrm{Katoh} \mathrm{A}$, Matsuyama K, Ikeda H, Hiyamuta $\mathrm{K}$, Toshima $\mathrm{H}$, et al. Disappearance of giant negative T waves in patients with the Japanese form of apical hypertrophy. J Am Coll Cardiol. 1995 Dec;26(7):1672-8. 
28. Fattori R, Biagini E, Lorenzini M, Buttazzi K, Lovato L, Rapezzi C. Significance of magnetic resonance imaging in apical hypertrophic cardiomyopathy. Am J Cardiol. 2010;105(11):1592-6.

29. Holloway CJ, Betts TR, Neubauer S, Myerson SG. Hypertrophic cardiomyopathy complicated by large apical aneurysm and thrombus, presenting as ventricular tachycardia. J Am Coll Cardiol. 2010;56(23):1961.

30. Maron BJ, Maron MS, Semsarian C. Genetics of hypertrophic cardiomyopathy after 20 years: clinical perspectives. J Am Coll Cardiol. 2012;60(8): 705-15.

31. Arad M, Penas-Lado M, Monserrat L, Maron BJ, Sherrid M, Ho CY, et al. Gene mutations in apical hypertrophic cardiomyopathy. Circulation. 2005;112(18):2805-11.

32. Gruner C, Care M, Siminovitch K, Moravsky G, Wigle ED, Woo A, et al. Sarcomere protein gene mutations in patients with apical hypertrophic cardiomyopathy. Circ Cardiovasc Genet. 2011;4(3):288-95.

33. Varma PK, Neema PK. Hypertrophic cardiomyopathy: part 1 - introduction, pathology and pathophysiology. Ann Card Anaesth. 2014;17(2):118-24.

34. Hughes SE. The pathology of hypertrophic cardiomyopathy. Histopathology. 2004 May;44(5):412-27.

35. Davies MJ, McKenna WJ. Hypertrophic cardiomyopathy-pathology and pathogenesis. Histopathology. 1995 Jun;26(6):493-500.

36. Cecchi F, Sgalambro A, Baldi M, Sotgia B, Antoniucci D, Camici PG, et al. Microvascular dysfunction, myocardial ischemia, and progression to heart failure in patients with hypertrophic cardiomyopathy. J Cardiovasc Transl Res. 2009 Dec;2(4):452-61.

37. Kim SH, Kim SO, Han S, Hwang KW, Lee CW, Nam $\mathrm{GB}$, et al. Long-term comparison of apical versus asymmetric hypertrophic cardiomyopathy. Int Heart J. 2013;54(4):207-11.

38. Lee CH, Liu PY, Lin LJ, Chen JH, Tsai LM. Clinical features and outcome of patients with apical hypertrophic cardiomyopathy in Taiwan. Cardiology. 2006;106(1):29-35.

39. Maron MS, Finley JJ, Bos JM, Hauser TH, Manning WJ, Haas TS, et al. Prevalence, clinical significance, and natural history of left ventricular apical aneurysms in hypertrophic cardiomyopathy. Circulation. 2008 Oct 7;118(15):1541-9.

40. Ridjab D, Koch M, Zabel M, Schultheiss HP, Morguet AJ. Cardiac arrest and ventricular tachycardia in Japanese-type apical hypertrophic cardiomyopathy. Cardiology. 2007;107(2):81-6.

41. Sakamoto T, Amano K, Hada Y, Tei C, Takenaka K, Hasegawa I, et al. Asymmetric apical hypertrophy: ten years experience. Postgrad Med J. 1986 Jun;62(728):567-70.

42. Chung T, Yiannikas J, Freedman SB, Kritharides L. Unusual features of apical hypertrophic cardiomyopathy. Am J Cardiol. 2010;105(6): 879-83.

43. Chen CC, Lei MH, Hsu YC, Chung SL, Sung YJ. Apical hypertrophic cardiomyopathy: correlations between echocardiographic parameters, angiographic left ventricular morphology, and clinical outcomes. Clin Cardiol. 2011;34(4):233-8.

44. Kim EK, Lee SC, Hwang JW, Chang SA, Park SJ, On YK, et al. Differences in apical and non-apical types of hypertrophic cardiomyopathy: a prospective analysis of clinical, echocardiographic, and cardiac magnetic resonance findings and outcome from 350 patients. Eur Heart J Cardiovasc Imaging. 2016;17(6): 678-86.

45. Okishige K, Sasano T, Yano K, Azegami K, Suzuki $\mathrm{K}$, Itoh K. Serious arrhythmias in patients with apical hypertrophic cardiomyopathy. Intern Med. 2001 May;40(5):396-402. 